\title{
Relações Institucionais Esperadas e Existentes na Disciplina Laboratório de Ensino de Matemática em um Curso de Graduação
}

\section{Expected and Existing Institutional Relations in Math Teaching Laboratory in a Undergraduate Course}

\author{
Laerte Silva da Fonseca ${ }^{1 *}$, Kleyfton Soares da Silva ${ }^{2}$ \\ ${ }^{1}$ Instituto Federal de Sergipe, Campus Aracaju \\ IInstituto Federal Goiano, Campus Campos Belos
}

* Autor para correspondência: laerte.fonseca@ifs.edu.br

\section{RESUMO}

Este artigo apresenta os resultados de uma análise institucional, cujo objetivo foi validar a institucionalização dos conhecimentos prévios esperados das disciplinas pré-requisitos de Laboratório de Ensino de Matemática. A metodologia considerou uma análise institucional fundamentada na Teoria Antropológica do Didático (CHEVALLARD, 1992), que foi conduzida em seis fases, sob alguns princípios da Engenharia Didática Clássica (ARTIGUE, 1998). Como fio condutor dessa empreitada, buscou-se responder à seguinte questão: os conhecimentos desenvolvidos nas três disciplinas pré-requisitos de Laboratório de Ensino de Matemática estão disponíveis no repertório dos estudantes matriculados e funcionando como suporte para novos conhecimentos esperados pela disciplina em questão? Os resultados revelaram a inexistência dos conhecimentos prévios esperados como disponíveis nos alunos para o bom desempenho da disciplina em análise. Dessa forma, a pesquisa mostrou a importância de uma mudança emergente nos hábitos de ensinar e aprender noções relacionadas à formação de professores de matemática.

Palavras-Chave: Análise Institucional; Laboratório de Ensino de Matemática; Desempenho Discente.

\begin{abstract}
This article presents the results of an institutional analysis whose objective was to validate the institutionalization of the previous knowledge expected from the prerequisite subjects of Mathematics Teaching Laboratory. The methodology considered an institutional analysis based on the Anthropological Theory of Didactics (CHEVALLARD, 1992), which was conducted in six steps, under some principles of Classical Didatic Engineering (ARTIGUE, 1998). As a guideline of this endeavor, the authors tried to answer the following question: is the knowledge developed in the three prerequisite subjects of Mathematics Teaching Laboratory available to students enrolled and functioning as support for new knowledge expected by the discipline in play? The results revealed that the previous knowledge expected as available in the students was not available for the good performance of the subject under analysis. In this way, the research revealed the importance of an emerging change in the habits of teaching and learning notions related to the mathematics teacher training.
\end{abstract}

Keywords: Institutional Analysis; Mathematics Teaching Laboratory; Student Performance.

\section{Introdução}

O objetivo geral desta pesquisa foi validar a institucionalização dos conhecimentos prévios esperados das disciplinas pré-requisitos de Laboratório de Ensino de Matemática de um curso de Licenciatura em Matemática do estado de Sergipe.

Esse alvo foi delimitado pela necessidade de compreender o nível das relações institucionais e pessoais esperadas e existentes (correspondência institucional) que revelam a situação cognitiva dos estudantes matriculados na disciplina Laboratório de Ensino de Matemática.

Com efeito, as determinações das relações citadas resultaram de esforços de pesquisa do campo da Didática da Matemática francesa por meio dos estudos de Chevallard (1992, 1994, 1998, 2007a, 
2007b) e Robert (1997, 1998).

A metodologia do presente estudo considerou uma análise institucional fundamentada na Teoria Antropológica do Didático (CHEVALLARD, 1992), que foi conduzida em seis fases, sob alguns princípios da Engenharia Didática Clássica (ARTIGUE, 1998). Como fio condutor dessa empreitada, buscou-se responder à seguinte questão: os conhecimentos desenvolvidos nas três disciplinas pré-requisitos de Laboratório de Ensino de Matemática estão disponíveis no repertório dos estudantes matriculados, e funcionando como suporte para novos conhecimentos esperados pela disciplina em questão?

Tal preocupação se justifica pela necessidade social de dispor no mercado de trabalho de profissionais da educação capazes de lidar com os problemas de aprendizagem matemática dos alunos da Educação Básica. Nesse sentido, a apropriação do embasamento teórico-metodológico da disciplina "Laboratório de Ensino de Matemática" pode auxiliar na diminuição de lacunas dessa aprendizagem, cada vez mais questionada, sempre que se verificam os índices do PISA ${ }^{3}$, por exemplo.

Recorreu-se a elementos da Didática da Matemática para subsidiar a organização, implementação e análise das situações relacionadas ao desempenho acadêmico de estudantes, por meio da verificação dos seus registros no exame do nível de funcionamento do conhecimento esperado. Por fim, discutem-se os resultados em que são revelados novos caminhos teóricos e metodológicos para uma análise institucional do desempenho acadêmico.

\section{Elementos da Didática da Matemática}

A existência e a disponibilidade de conteúdos na estrutura cognitiva do estudante podem facilitar o processo de evocação de informações para a escolha adequada de técnicas para a resolução de tarefas. Nesse sentido, para alicerçar o diálogo entre tipos de objetos que recrutem a característica da evocação, optou-se pelos conhecimentos teóricos de duas vertentes da Didática da Matemática.

Primeiramente, é importante considerar alguns elementos da Teoria Antropológica do Didático
(TAD) de Chevallard (1992) para definir as características da atividade matemática, ponto inicial do referido pesquisador que buscou matematizá-la, utilizando-se, principalmente, da definição de função de duas variáveis. Em segundo lugar, inserem-se os Níveis de Funcionamento do Conhecimento (NFC) de Robert (1997, 1998), por entender que as tarefas que mobilizam a atividade matemática podem ser apresentadas em diferentes graus; e, por fim, os princípios da Engenharia Didática Clássica de Artigue (1998), que serviram para estruturar os procedimentos metodológicos da pesquisa em tela.

\section{Teoria Antropológica do Didático (TAD)}

Como se fosse possível visualizar diariamente a movimentação cotidiana dos seres humanos, o pesquisador e matemático francês Yves Chevallard observou com as lentes de um matemático que tais movimentos refletem a Atividade Humana $(\mathrm{AH})$ que coabita em Instituições Sociais (IS), em que, especificamente, a Atividade Matemática (AM) é um caso particular entre as anteriores, podendo ser representada como: $\mathrm{AM}=(\mathrm{AH} \cap \mathrm{IS})$.

Sendo a escola um tipo de IS e realizando-se dentro dela inumeráveis $\mathrm{AHs}$, a AM ocorre em momentos especiais, pois se somam esforços institucionalizados do professor com as expectativas dos alunos para realizarem com sucesso (ou não) as tarefas apresentadas. Motivado por essas singularidades, o referido pesquisador denominou de praxeologia (ou organização praxeológica) um padrão único para analisar as variadas $\mathrm{AHs}$, constituindo-se sua existência, dessa forma, uma premissa basal da Teoria Antropológica do Didático.

Para leitores que desconhecem essa teoria, vale a pena justificar sua etiologia quando foi decomposta pelo autor em "praxe + o + logia", do grego, práxis (ação, hábito ou prática) + logos (conhecimentos, ciências ou teorias). Valendo-se dessa prerrogativa, Chevallard (1998) percebeu que uma ação (ou práxis) é constituída de dois elementos, a saber: noções de tarefas $(t)$ e tipos de tarefas $(\mathrm{T})$ em que $t \in \mathrm{T}$, ambas exibidas por 
um verbo no infinitivo, por exemplo: calcular o $\log _{4} 20$.

Por outro lado, Chevallard (1998) buscou compreender e aplicar o sentido e significado de logos (conhecimento) sempre que estivesse atrelado a uma tarefa $t$. Dessa análise resultou que, nos bastidores da realização de $t$, existe um discurso matemático, por exemplo, fundamentado e disponível no âmago do conhecimento utilizado, buscando justificativas e interpretação para a ação inicial. Nesta ordem, o autor denominou de técnica $(\tau)$ - do grego tekhnê, saber-fazer, ou ainda, maneira específica de fazer algo.

Conforme salienta Bittar (2017), configura-se a parte primeira de uma praxeologia relacionada a um tipo de tarefa $\mathrm{T}$ que contém uma técnica ( $\tau$ ) respectiva a $\mathrm{T}$ : o bloco prático-técnico $[\mathrm{T} / \tau]$, denominado por Chevallard (1998) de saber-fazer. Entretanto, observa o pesquisador que o discurso racional não aparente empregado sobre a técnica ( $\tau)$ tem um caráter mais amplo e profundo, de tal modo que Chevallard (1998) denominou de tecnologia $(\theta)$ que varia de acordo com a IS e tem como função primordial tornar inteligível $(\tau)$ e explicar por que isso ocorre.

Dentre várias funções de tecnologia $(\theta)$ estão: justificar $(\tau)$ fornecendo o que é pretendido, explicar para tornar inteligível e esclarecer $(\tau)$, quando, observa o autor, privilegia-se a exigência da demonstração, em detrimento da explicação; a produção de técnicas.

Como toda $(\theta)$ é dinâmica e alicerça-se sobre uma fonte de conhecimento que admite questionamentos dos próprios discursos, tecnologia da tecnologia, Chevallard (1998) denominou-o de teoria $(\Theta)$, constituindo-se da segunda parte de uma praxeologia de certa tarefa. Portanto, o pesquisador denominou esse segundo bloco de bloco tecnológico-teórico $[\theta / \Theta]$, sinônimo de saber.

Apresentado o modelo praxeológico de Chevallard (1998), faz-se necessário retomar que o mesmo autor buscou aplicá-lo para analisar AM, em que define três termos primitivos: os objetos $\mathrm{O}$, as pessoas $\mathrm{X}$ e as instituições I, estritamente nessa ordem.
Recorrendo-se a Chevallard (1992), os objetos constituem em si mesmo material de base de toda construção teórica. Para ele, tudo é objeto: as pessoas X, as instituições I são, por exemplo, de um tipo especial. Considerando esse ponto de partida, impetra uma condição de existência: um objeto só existirá desde que uma pessoa $\mathrm{X}$ ou uma instituição I reconheça tal objeto como existente. Em Fonseca (2015, p. 155), por exemplo,

[...] é necessário e suficiente existir pelo menos uma relação de $\mathrm{O}$ com $\mathrm{X}, \mathrm{R}(\mathrm{X}, \mathrm{O})$, ou de $\mathrm{O}$ com $\mathrm{I}, \mathrm{RI}(\mathrm{O})$, para que $\mathrm{O}$ exista. Serão essas noções que permitirão o mapeamento analítico das praxeologias existentes na Atividade Matemática, especificamente, no campo das Funções Trigonométricas.

Como matemático, Chevallard (2007a) defende que o uso da noção de relação a um objeto remonta e viabiliza a concepção de problemas variados, pois existe uma precisão delicada nas definições matemáticas. Em favor dessa causa, Fonseca (2015, p. 155) postula que "a explicitação da dinâmica entre a pessoa e o objeto, seu modo de pensar e, até mesmo, idealização de objetivos futuros" são exemplos $\mathrm{R}(\mathrm{X}, \mathrm{O})$.

Dessa forma, a noção mais límpida de praxeologia, para compreender essa relação $\mathrm{R}(\mathrm{X}, \mathrm{O})$ ou $\mathrm{RI}(\mathrm{O})$, repousa sobre as circunstâncias durante a análise da gênese ou evolução dessas relações e, por isso, defende Chevallard (1998) que é notório observá-las em atividades que possam ativar tal objeto.

Entretanto, para conhecer melhor a natureza dos elementos que constituem as $\mathrm{R}(\mathrm{X}, \mathrm{O})$ ou $\mathrm{RI}(\mathrm{O})$, o pesquisador buscou respostas para as seguintes questões: De que é feita uma técnica? De que ingredientes ela é composta? Em que consiste a "execução" de uma técnica? (CHEVALLARD, 1994).

Sob o abrigo de sua teoria praxeológica, o autor estabelece diferenças essenciais entre dois tipos específicos de objetos: os objetos ostensivos e os objetos não ostensivos. Chevallard (1994) define objetos ostensivos aqueles que apresentam uma forma sensível ou material como, por exemplo, ostensivos 
materiais: uma caneta, um compasso etc.; ostensivos gestuais: os gestos; ostensivos discursivos: as palavras e, mais genericamente, o discurso; ostensivos gráficos: os esquemas, desenhos, grafismos; ostensivos escriturais: as escritas e os formalismos.

Baseado nessas condições, vale a pena destacar que os objetos ostensivos podem ser manipulados, enquanto os objetos não ostensivos (noções, conceitos, ideias etc.) são somente evocados através da manipulação dos ostensivos possivelmente associados.

Assim, Chevallard (1994) ressalta a existência de uma dialética necessária e complexa entre o sistema de ostensivos e os não ostensivos: "quanto maior domínio sobre os não ostensivos (as noções) e, por isso supostamente disponíveis, maior a manipulação dos ostensivos associados para evocá-los" (FONSECA, 2015, p. 158).

Ao que tudo indica, é uma das preocupações de Chevallard (1994) sobre a Atividade Matemática (AM) a ausência, em muitos contextos, de valorização do papel dos objetos ostensivos. Por exemplo, tais objetos comumente estão disponibilizados no Laboratório de Ensino de Matemática, mas quase sempre são desconsiderados pelos professores. Para esse pesquisador, isso se constitui em um preconceito cultural e satisfaz um ponto de vista tradicional da AM ou, de modo mais geral, da Atividade Humana $(\mathrm{AH})$, considerando a valorização dos objetos não ostensivos (evocáveis) como necessários e essenciais, em detrimento aos objetos ostensivos que serviriam apenas de contingentes e não seriam essenciais.

Uma observação na qual Chevallard (1994) se faz categórico é quando defende que, para mobilizar no outro a compreensão de uma noção matemática, é preciso pinçar a técnica que melhor reflita a tarefa em jogo, pois esta irá depender de um complexo sistema de objetos ostensivos e objetos não ostensivos, ativados, muitas vezes, pela mesma técnica ou similares.

\section{Níveis de Funcionamento do Conhecimento (NFC)}

Considerando que na sala de aula de Matemática existem diferentes tarefas para 60 auxiliarem no desenvolvimento cognitivo dos alunos, faz-se necessário tornar possível o diálogo entre os objetos não ostensivos (possíveis de serem existentes na memória de longo prazo) e os objetos ostensivos possíveis de serem manipulados (caso estejam disponíveis). A pesquisadora francesa Aline Robert vislumbrou a possibilidade de investigar como essas tarefas expostas aos estudantes poderiam ser estruturadas para facilitar a compreensão e o domínio dos conteúdos matemáticos.

Robert (1997, 1998) postula que os Níveis de Funcionamento do Conhecimento podem ser compreendidos como um conjunto de ferramentas desenvolvidas, como resultado de uma análise epistemológica e didática e, com isso, pode-se estabelecer uma hierarquia dos conhecimentos matemáticos que serão apresentados aos alunos da Educação Básica, por exemplo.

Tais instrumentos ajudam na organização de cenários de aprendizagem, cuja investigação epistemológica do conhecimento contribuiu significativamente para analisar a evolução do mesmo a partir de três níveis, a saber: Nível Técnico (NT), Nível Mobilizável (NM) e Nível Disponível (ND).

Para a autora, o objetivo principal dessas ferramentas é identificar o nível operacional de funcionamento dos conhecimentos nas tarefas apresentadas aos discentes, seja qual for o locus e natureza dela. Dessa forma, Robert $(1997,1998)$ defende a existência de uma hierarquia natural entre esses níveis que facilitaria, se apresentados na ordem esperada, a compreensão das noções matemáticas.

O nível técnico (NT) encontra-se na base dessa estrutura, pois corresponde, segundo Robert (1997), à aplicação imediata de teoremas, propriedades, definições e fórmulas, na resolução de uma tarefa primeira que intenta estimular a Atividade Matemática (AM) dos alunos que representa, nesse nível, um trabalho isolado, local e concreto.

No segundo nível, o mobilizável (NM), a autora define que existe um mecanismo mais extenso que o NT por meio de aplicações simples, em que os atributos sejam interpolados um por vez, de forma que esteja explicitamente descrito o questionável. 
O terceiro nível, Robert denominou de disponível (ND): nele, o aluno deve dispor da capacidade de resolver, sem a mínima pista acerca do conteúdo, esforçando-se para descobrir sozinho quais são os conhecimentos necessários (ou esperados) para a resolução da tarefa. Assim, fica implícito que neste nível o aluno deve ter disponíveis em sua memória de longo prazo teoremas, técnicas e estratégias para escolhê-los adequadamente.

\section{Metodologia}

\section{Engenharia Didática Clássica}

Quanto aos procedimentos metodológicos, encaminhou-se a investigação sob alguns princípios da Engenharia Didática Clássica ${ }^{4}$ (EDG) da francesa Michèle Artigue (1998), que consiste no gerenciamento de elementos metodológicos para o planejamento (análise preliminar), elaboração (análises a priorn), experimentação, análise e validação (análises a posteriori) de Atividade Matemática (AM). Buscou-se alcançar o objetivo desta pesquisa considerando alguns princípios da engenharia didática, desenvolvendo-se as seguintes fases:

\section{Análises prévias}

Fase 1: Desenvolvimento de um Exame de Nível de Funcionamento do Conhecimento Esperado (ENFCE), contendo questões sobre as três disciplinas pré-requisitos.

Fase 2: Estabelecimento do Índice de Compatibilidade Institucional Esperada (ICIE), considerando a paridade entre o período institucionalmente estabelecido para o aluno cursar as disciplinas pré-requisitos com o período efetivo em que essas disciplinas foram cursadas. Ou seja:

- Se o aluno cursou as 03 disciplinas pré-requisitos nos períodos institucionalmente estabelecidos, o ICIE é de 100\%;

- Se o aluno cursou 02 disciplinas pré-requisitos nos períodos institucionalmente estabelecidos, o ICIE é de 66\%;

- Se o aluno cursou apenas 01 disciplina pré-requisito no período institucionalmente estabelecido, o ICIE é de 33\%;
- Se o aluno não cursou nenhuma das 03 disciplinas pré-requisitos nos períodos institucionalmente estabelecidos, o ICIE é de $0 \%$.

\section{Concepção e análise a priori}

Fase 3: Determinação de uma relação entre o ICIE e os resultados do ENFCE.

\section{Experimentação}

Fase 4: Aplicação do ENFCE para todos os alunos da disciplina Laboratório de Ensino de Matemática.

\section{Análise a posteriori e validação}

Fase 5: Correção do ENFCE dos alunos.

Fase 6: Análise dos resultados, conforme Dias (1998), por meio do cruzamento de dados obtidos a partir do ENFCE, ICIE, Relações Institucionais Esperadas e Existentes, Relações Pessoais Existentes de acordo com a TAD de Chevallard (1992, 1994, 1998).

\section{Resultados}

Fase 1: Elaborou-se um Exame de Nível de Funcionamento do Conhecimento Esperado (ENFGE), contendo questões sobre as três disciplinas pré-requisitos (Apêndice A). Tal instrumento de investigação considerou a disposição mostrada na tabela 1 .

Fase 2: Determinou-se o Índice de Compatibilidade Institucional Esperada (ICIE), considerando a paridade entre o período institucionalmente estabelecido para o aluno cursar as disciplinas pré-requisitos e o período efetivo em que essas disciplinas foram cursadas (Tabela 2).

Fase 3: O ENFCE foi disponibilizado para todos os onze alunos da disciplina Laboratório de Ensino de Matemática. Foi aplicado a dez estudantes voluntários da disciplina. Registrou-se a ausência de um estudante por abandono/trancamento de matrícula. Por questões éticas, suas identidades foram preservadas, optando-se por codificá-las em: A1, A2, A3, A4, A5, A6, A7, A8, A9, A10.

Fase 4: A correção e o mapeamento das respostas dos participantes (alunos voluntários) foram identificados (Tabela 4). 


\begin{tabular}{|c|c|c|}
\hline $\begin{array}{c}\text { Disciplinas pré-requisitos de } \\
\text { Laboratório de Ensino de Matemática }\end{array}$ & $\begin{array}{c}\text { Nível de Funcionamento } \\
\text { do Conhecimento } \\
\text { Esperado (NFCE) }\end{array}$ & Questões do ENFCE \\
\hline $\begin{array}{c}\text { Matemática do Ensino Fundamental } \\
\text { (pré-requisito 1) }\end{array}$ & TÉCNICO & 1 \\
\hline $\begin{array}{c}\text { Matemática do Ensino Médio I } \\
\text { (pré-requisito 2) }\end{array}$ & MOBILIZÁVEL & 2 \\
\hline $\begin{array}{c}\text { DISPONÍVEL } \\
\text { Didática e Práxis Pedagógica } \\
\text { (pré-requisito 3) }\end{array}$ & MOBILIZÁVEL & 3 \\
\hline & TÉCNICO & 4 \\
\hline
\end{tabular}

Tabela 1 - Funcionamento do ENFCE. Fonte: Os autores (2019).

\section{Disciplinas pré-requisitos cursadas nos períodos institucionalmente estabelecidos pela matriz curricular do curso de Licenciatura em Matemática do IFS}

0

Tabela 2 - Determinantes do Índice de Compatibilidade Institucional Esperada (ICIE). Fonte: Os autores (2019).

\begin{tabular}{|c|c|c|c|c|}
\hline \multirow{2}{*}{ Participantes } & \multicolumn{2}{|c|}{$\begin{array}{c}\text { Avaliação das Questões (1 a 10), sendo: } \\
\text { DE (Dentro do Esperado); FE (Fora do Esperado) }\end{array}$} & \multirow{2}{*}{ ICIE (\%) } \\
\cline { 2 - 5 } & Pré-requisito 1 & Pré-requisito 2 & Pré-requisito 3 & \\
\hline A1 & DE & DE & DE & 100 \\
\hline A2 & DE & DE & DE & 100 \\
\hline A3 & DE & DE & DE & 100 \\
\hline A4 & DE & DE & DE & 100 \\
\hline A5 & DE & DE & DE & 100 \\
\hline
\end{tabular}




\begin{tabular}{|c|c|c|c|c|}
\hline \multirow{2}{*}{ Participantes } & \multicolumn{2}{|c|}{$\begin{array}{c}\text { Avaliação das Questões (1 a 10), sendo: } \\
\text { DE (Dentro do Esperado); FE (Fora do Esperado) }\end{array}$} & \multirow{2}{*}{ ICIE (\%) } \\
\hline & Pré-requisito 1 & Pré-requisito 2 & Pré-requisito 3 & \\
\hline A6 & DE & FE & DE & 66 \\
\hline A7 & DE & FE & DE & 66 \\
\hline A8 & DE & DE & DE & 100 \\
\hline A9 & DE & FE & DE & 66 \\
\hline A10 & DE & FE & FE & 33 \\
\hline
\end{tabular}

Tabela 3 - Aplicação do ICIE sobre o Histórico Escolar dos voluntários. Fonte: Os autores (2019).

\begin{tabular}{|c|c|c|c|c|c|c|c|c|c|c|c|}
\hline \multirow{3}{*}{ Participantes } & \multicolumn{10}{|c|}{$\begin{array}{c}\text { Avaliação das Questões (1 a 10), sendo: } \\
\text { C (correto), E (errado), B (em branco), C/2 (50\%), C/4 (25\%) }\end{array}$} & \multirow{3}{*}{$\begin{array}{c}\text { Índice de } \\
\text { respostas } \\
\text { corretas } \\
(\%)\end{array}$} \\
\hline & \multicolumn{3}{|c|}{ Pré-requisito 1} & \multicolumn{3}{|c|}{ Pré-requisito 2} & \multicolumn{4}{|c|}{ Pré-requisito 3} & \\
\hline & 1 & 2 & 3 & 4 & 5 & 6 & 7 & 8 & 9 & 10 & \\
\hline A1 & B & $B$ & $E$ & B & B & $B$ & $\mathrm{E}$ & C & C & B & 20 \\
\hline $\mathrm{A} 2$ & B & $E$ & $\mathrm{C} / 2$ & B & C & $E$ & C & C & C & B & 40 \\
\hline $\mathrm{A} 3$ & $\mathrm{E}$ & B & $\mathrm{C} / 2$ & B & B & B & $E$ & C & C & B & 20 \\
\hline A4 & C & C & C & C & C & $E$ & B & B & B & B & 50 \\
\hline A5 & C & C & $C / 4$ & $E$ & C & $E$ & $E$ & C & $E$ & $E$ & 40 \\
\hline A6 & B & $\mathrm{E}$ & $C / 4$ & B & $E$ & $\mathrm{C}$ & C & $E$ & C & B & 30 \\
\hline A7 & B & B & $E$ & B & $E$ & $E$ & C & C & $E$ & $\mathrm{E}$ & 20 \\
\hline A8 & B & $B$ & $E$ & $B$ & B & $B$ & C & C & C & $B$ & 30 \\
\hline A9 & B & B & $C / 4$ & $B$ & $E$ & $B$ & $E$ & C & $E$ & $E$ & 10 \\
\hline A10 & B & $B$ & $E$ & $B$ & $B$ & $B$ & $C$ & C & $E$ & $E$ & 20 \\
\hline
\end{tabular}

Tabela 4 - Mapeamento avaliativo das respostas dos participantes. Fonte: Os autores (2019).

Número Total de Respostas $=100$

Número Total de Respostas do Pré-requisito $1=30$

Número Total de Respostas do Pré-requisito $2=30$

Número Total de Respostas do Pré-requisito $3=40$

Número de Respostas Corretas do Pré-requisito $1=\mathrm{n}$

Número de Respostas Corretas do Pré-requisito $2=\mathrm{m}$

Número de Respostas Corretas do Pré-requisito 3 = p
Relações imediatas:

$\mathrm{n}=\mathrm{m}=5$;

$p=18$

$\mathrm{p}>\mathrm{n}+\mathrm{m}$;

$\% n=\% m=16,6 \%$

$\% p=45 \%$ 


\begin{tabular}{|c|c|c|c|}
\hline Disciplinas & NFCEx & $\begin{array}{c}\text { Número de alunos } \\
\text { que acertaram }\end{array}$ & Participantes \\
\hline $\begin{array}{c}\text { Matemática do } \\
\text { Ensino Fundamental } \\
\text { (pré-requisito 1) }\end{array}$ & TÉCNICO & 2 & A4 e A5 \\
\hline $\begin{array}{c}\text { Matemática do } \\
\text { Ensino Médio I } \\
\text { (pré-requisito 2) }\end{array}$ & DISPONÍVEL & 2 & A4 e A5 \\
\hline $\begin{array}{c}\text { MÓCNICO } \\
\text { Didática e Práxis }\end{array}$ & DISPONÍVEL & 1 & A4 \\
\hline $\begin{array}{c}\text { Pedagógica } \\
\text { (pré-requisito 3) }\end{array}$ & MOBILIZÁVEL & 1 & A6 \\
\hline
\end{tabular}

Tabela 5 - Níveis do Funcionamento do Conhecimento Existente = NFCEx (considerando-se a existência do NFCE associado no Tabela 1). Fonte: Os autores (2019).

Conforme verificado, levando-se em conta o resultado dos dez voluntários da pesquisa, o percentual de acerto das questões do pré-requisito 1 e 2 foi 16,6\%, enquanto o de acerto do pré-requisito 3 foi de $45 \%$.

Fase 5: Foi determinada uma relação entre $o$ ICIE e o ENFCE, considerando o histórico dos participantes, bem como os resultados obtidos no referido exame.

Observando os resultados apresentados nas Tabelas 2 e 3, verificaram-se as seguintes relações:

- Os participantes A4 e A5 estão alinhados com as expectativas institucionais apenas nas disciplinas Matemática do Ensino Fundamental (pré-requisito 1) e Matemática do Ensino Médio I (pré-requisito 2). Eles cursaram-nas nos períodos previstos na matriz curricular do curso com 100\% do NFCE para A4 e 66\% do NFCE para A5;

- Dispor de $100 \%$ do ICIE não potencializa, plenamente, os NFCE em todas as disciplinas pré-requisitos;

- Verificou-se que o NFCE quando é alcançado nas disciplinas Matemática do Ensino Fundamental (pré-requisito 1) e Matemática do Ensino Médio I (pré-requisito 2) não corresponde à disciplina Didática e Práxis Pedagógica e vice-versa.
Fase 6: Para que os resultados pudessem ser analisados, estabeleceram-se as principais categorias (CA) consideradas por uma análise institucional, segundo os parâmetros de Chevallard (1992, 1994, 1998).

$\mathrm{Na}$ Teoria Antropológica do Didático (TAD) de Chevallard (1992, 1994, 1998, 2007a, 2007b), são valorizadas definições que permitem analisar a aproximação ou o distanciamento em que um objeto se encontra em relação a uma instituição ou a uma pessoa. No caso deste estudo, tal objeto foi descrito como o NFCE, e as categorias foram:

CA1 - Relações Institucionais Esperadas, definidas a partir da correspondência entre as expectativas contidas no PPG e no PROGRAMA DE ENSINO das disciplinas pré-requisitos;

CA2 - Relações Institucionais Existentes, definidas a partir da correspondência entre as expectativas contempladas pelo PROGRAMA DE ENSINO e um Livro Didático indicado nas referências dos respectivos programas;

CA3 - Relações Pessoais Existentes, definidas a partir da correspondência entre as expectativas contempladas pelo Livro Didático analisado em CA2 e o ENFGE. 
Na sequência, a análise dos resultados priorizou, conforme Dias (1998), o cruzamento dos dados obtidos a partir do ICIE, ENFCE e das categorias acima.

\section{Análises e discussão}

\section{Análise 1:}

$\mathrm{O}$ estudante A5 foi o único que não deixou de responder uma única questão. Conforme Chevallard (1992), existe certa correspondência entre CA1, CA2 e CA3, considerando-se as disciplinas de Matemática do Ensino Fundamental (pré-requisito 1) e Matemática do Ensino Médio I (pré-requisito 2), o que não ocorre com a disciplina pré-requisito 3, Didática e Práxis Pedagógica. Apoiando-se em Chevallard (1994), verificou-se a existência (utilização) de diferentes técnicas para a resolução da tarefa que objetivava identificar a articulação entre a evocação de objetos não ostensivos e a manipulação de objetos ostensivos diante de uma demonstração matemática que se utilizasse do método indutivo (questões $1 \mathrm{e}$ 2). Outro ponto que cabe ressaltar refere-se ao Nível de Funcionamento do Conhecimento de A5 observado pela associação das tabelas 1 e 2 . Nesse sentido, o funcionamento do conhecimento nos níveis verificados (técnico e mobilizável) revela a capacidade de A5 de evocar e manipular os princípios, definições e propriedades algébricas utilizadas nas demonstrações por indução. No entanto, o referido estudante ainda não desenvolveu a capacidade para resolver tarefas mais complexas (nível disponível), em que não existem indicações de nenhuma espécie nos enunciados.

\section{Análise 2:}

Primeiramente, verificou-se que $90 \%$ dos participantes deixaram de tentar resolver pelo menos alguma questão, exceto o estudante A5 (Análise 1).

$\mathrm{O}$ estudante A4 foi o único que alcançou $83,3 \%$ de correção nas disciplinas pré-requisitos 1 e 2, comprovando quase a completa existência do nível disponível da escala de Robert (1997, 1998). Na contramão desse êxito, demonstrou completa ausência de todos os Níveis de Funcionamento do Conhecimento de Robert (1997, 1998) no pré-requisito 3 , quando todas as questões foram deixadas em branco.

No que se refere à TAD (Chevallard, 1992), é forte a indicação de correspondência entre CA1, CA2 e CA3 e as disciplinas de Matemática do Ensino Fundamental (pré-requisito 1) e Matemática do Ensino Médio I (pré-requisito 2). A clareza da utilização de diferentes técnicas, para a resolução das tarefas anunciadas nas questões contempladas, revelou a bricolagem entre os elementos do saber matemático evocado, tecnologia e teoria, desenvolvidas por Chevallard (1994) para justificar a existência de técnicas (modo de fazer) empregadas na solução das referidas tarefas.

Nesta etapa da pesquisa, destacaram-se os principais aspectos da tabela 3 que chamaram atenção enfocando-se o NFGE.

\section{Análise 3:}

$\mathrm{O}$ estudante $\mathrm{A} 6$ foi o único que acertou a questão 6. Enquadrada no nível técnico de Robert (1997, 1998), consistindo em evocar os não ostensivos (definição e propriedades esperadas para as funções polinomiais do segundo grau) e a aplicação do entendimento da construção de gráfico da função inversa associada. Foi preocupante identificar que 90\% dos participantes não dominam as técnicas de construção e esboço de gráficos de funções consideradas básicas. Isso demonstra que, segundo Chevallard (1992), o saber matemático (tecnologia-teoria) das funções - justificativas, explicação e produção das técnicas para esboço e construção de gráficos; discurso tecnológico algébrico ou tecnologia da tecnologia algébrica, respectivamente - não está disponível para os referidos estudantes. Ao mesmo tempo, A6 não dispõe dos níveis mobilizável e disponível às outras cinco questões referentes aos saberes matemáticos.

\section{Análise 4:}

A questão 8 foi a mais respondida corretamente $(80 \%$ dos estudantes). Ao que tudo indica, os saberes pedagógicos foram mais absorvidos, 
comparando-se com os saberes matemáticos. Há uma fina sintonia entre as categorias CA1, CA2 e CA3, enfocando-se a disciplina "Didática e Práxis Pedagógica", demonstrando que os licenciandos estão mais aptos para lidarem com aspectos pedagógicos da sala de aula comparando-se com os domínios matemáticos esperados pelas disciplinas Matemática do Ensino Fundamental e Matemática do Ensino Médio I. Ainda assim, prevalece o nível mobilizável para justificar o estágio do NFG de Robert (1997, 1998).

\section{Análise 5:}

A questão 10 foi a única para a qual não houve resposta correta. Como uma tarefa pedagógica do nível disponível, objetivava avaliar a capacidade dissertativa dos participantes, esperando-se, sempre que possível, a evocação de argumentos de autoridade articulados com alguns aspectos sócio-históricos disponíveis nos participantes. Isso demonstra que ainda é frágil a correspondência entre as categorias CA1, GA2 e CA3, mesmo conservando-se o ICIE.

\section{Considerações Finais}

A motivação desta pesquisa, que buscou validar a institucionalização dos conhecimentos prévios esperados das disciplinas pré-requisitos de Laboratório de Ensino de Matemática, partiu da preocupação em avaliar o nível de correspondência institucional entre relações institucionais e pessoais esperadas e existentes que justificassem o estado do desenvolvimento intelectual dos estudantes matriculados na disciplina em tela.

Como base teórica, considerou os investimentos científicos da Didática da Matemática francesa por meio dos estudos de Chevallard (1992, 1994, 1998, 2007a, 2007b) e Robert (1997, 1998). Concluiu-se que, apesar de as relações institucionais buscarem atender os parâmetros relacionados aos NFGE, as relações pessoais existentes demonstraram serem insuficientes para atingirem um funcionamento desejado, sinônimo de aprendizagem.

Nesse sentido, aponta-se como sugestão a elaboração de planos de ação e desenvolvimento de trabalhos visando à valorização da formação de memórias duradouras (objetos não ostensivos) necessárias para a assimilação das noções matemáticas e didáticas imprescindíveis na formação inicial dos professores.

\section{Notas}

${ }^{1}$ Livre Docente pela Emil Brunner World University ${ }^{\circledR} \quad$ (EBWU, Maiami, Flórida/EUA); Doutor Honoris Causa (EBWU); Laureado com o Título de Notório Saber (EBWU); Pós-Doutor em Psicologia e Neurociência Cognitiva (EBWU); Pós-Doutor em Educação Matemática (UNIAN/SP); Doutor em Educação Matemática (UNIAN/SP, UCBLyon 1/ FR); Mestre em Ensino de Ciências e Matemática (UFS), Mestre em Educação (UFS); Especialista em: Neuropsicologia, Neuroaprendizagem, Psicopedagogia (Institucional e Clínica), Ensino de Matemática e em Educação Matemática; Psicólogo (ESTÁCIO-SE), Licenciado em Matemática (UFS); Especialização em Terapia Cognitivo-Comportamental (PUC-RG, em andamento); Prof. Titular de Educação Matemática (IFS/Campus Aracaju); Professor Homenageado: Título de Honra ao Mérito pelas valiosas contribuições prestadas ao IFS (REITORIA/IFS); Docente e pesquisador do PPGECIMA (UFS); Criador e Editor-Chefe de Caminhos da Educação Matemática em Revista (impressa, 2008 e online, 2014/IFS); Coordenador do GEPEM - Grupo de Estudos e Pesquisa em Educação Matemática (IFS); Coordenador do neuroMATH - Grupo de Pesquisa em Desenvolvimento Neurocognitivo da Aprendizagem Matemática (IFS). E-mail: laerte. fonseca@ifs.edu.br

${ }^{2}$ Professor de Química do Instituto Federal Goiano, Campus Campos Belos. Doutorando em Ensino de Ciências na USP; Mestre em Ensino de Ciências e Matemática pela UFS, Especialista em Neurociência e Educação; Licenciado em Química pelo Instituto Federal de Alagoas. E-mail: kley.soares@hotmail.com.

${ }^{3} \mathrm{O}$ Programa Internacional de Avaliação de 
Alunos é uma rede mundial de avaliação de desempenho escolar.

${ }^{4}$ Resumidamente, a EDG serve como um guia na determinação de técnicas, métodos e recursos de ensino reprodutíveis. No âmbito desta pesquisa, a EDC tem um caráter investigativo, onde "procura-se fazer emergir fenômenos didáticos e estudá-los, com a intenção de um avanço nos resultados da investigação, por meio de experimentações montadas em função da questão de pesquisa, sem preocupação imediata de uma eventual divulgação mais ampla das situações utilizadas" (ALMOULOUD \& SILVA, 2012).

${ }^{5} \mathrm{O}$ NFGE foi considerado inspirando-se nos Níveis de Funcionamento do Conhecimento de Robert (1997, 1998).

\section{Referências Bibliográficas}

ALMOULOUD, S. A. \& SILVA, M. J. F. "Engenharia Didática: Evolução e Diversidade". Revemat: Revista Eletrônica de Educaşão Matemática, Florianópolis, vol. 7, n. 2, 2012, pp. 22-52.

ARTIGUE, M. "Ingénierie Didactique". Recherches en Didactique des Mathématiques. Grenoble: La Pensée Sauvage-Éditions, vol. 9, n. 3, 1998, pp. 281-308.

BITTAR, M. A "Teoria Antropológica do Didático como Ferramenta Metodológica para Análise de Livros Didáticos". Zetetike, vol. 25, n. 3, pp. 364, 27 dez. 2017.

CHEVALLARD, Y. "Analyse des Pratiques Enseignantes et Didactique des Mathématiques: LApproche Anthropologique". Cours Donné à L'Université d'Été Analyse des Pratiques Enseignantes et Didactique des Mathématiques, La Rochelle, 4-11 juillet 1998; paru dans les actes de cette université d'été, IREM de Clermont-Ferrand, 1998, pp. 91-120.
CHEVALLARD, Y. "Concepts Fondamentaux de la Didactique: Perspectives Apportées par une Approche Anthropologique". Recherches en Didactique des Mathématiques. Grenoble: La Pensée Sauvage, 1992.

CHEVALLARD, Y. "Le Développement Actuel de la TAD: Pistes et Jalons". Notes pour un exposé donné le 6 juin 2007 au Séminaire Didirem (Université Paris 7), 2007a.

CHEVALLARD, Y. "Les Mathématiques dans les Formations Universitaires: un Schéma Alternative". Notes pour exposé présenté au séminaire. Mathématiques et Sciences Humaines de la Faculté des Sciences de Luminy, Méditerranée, 2007b.

CHEVALLARD, Y. "Ostensifs et Non-Ostensifs dans l'Activité Mathématique". Séminaire de l'Associazione Mathesis, Turin, 3 février 1994. Actes du Séminaire 1993-1994, pp. 190-200.

DIAS, M. A. Les Problèmes d'Articulation entre Points de Vue "Cartésien" et "Paramétrique" dans l'Enseignement de l'Algèbre Linéaire. Thése de doctorat, Université de Paris VII Denis Diderot, Paris, 1998.

FONSECA, L. S. Um Estudo sobre o Ensino de Funções Trigonométricas no Ensino Médio e no Ensino Superior no Brasil e França. Tese de Doutorado em Educação Matemática. Universidade Anhanguera de São Paulo, São Paulo (SP), vol. 1, 2015, pp. 495.

ROBERT, A. "Outils d'Analyse des Contenus Mathématiques à Enseigner au Lycée et à l'Université". Recherches en Didactique des Mathématiques, [S.I.], vol. 18, n. 2, 1998, pp. 139-190.

ROBERT, A. "Quelques Outils d'Analyse Epistemologique et Didactique de Connaissances Mathématiques à Enseigner au Lycée et à l'Université". Actes de la IX Ecole d'Été de Didactique des Mathématiques. França: Houlgate, 1997. 


\section{Apêndice A}

\section{Exame do Nível de Funcionamento do Conhecimento Esperado (NFGE) \\ Curso de Licenciatura em Matemática \\ Disciplina: Laboratório de Ensino de Matemática}

Aluno (a):

1) Demonstrar, por indução matemática, que se $S_{n}=\frac{1}{1 \cdot 2}+\frac{1}{2 \cdot 3}+\frac{1}{3 \cdot 4}+\cdots+\frac{1}{n(n+1)}$, então

$$
S_{n}=\frac{n}{n+1}
$$

2) Mostrar que $1+3+5+\cdots+(2 \mathrm{n}-1)=\mathrm{n}^{2}, \forall \mathrm{n} \in \mathrm{IN}$.

3) Avaliar os itens relacionados à proposição abaixo como verdadeiro (V) ou falso $(\mathrm{F})$ :

PROPOSIÇÃO: Sejam a e b inteiros não nulos. Então valem as seguintes propriedades:
(i) $\operatorname{mmc}(\mathrm{a}, \mathrm{b}) \leq \max \{|\mathrm{a}|,|\mathrm{b}|\}$
(ii) é único o $\mathrm{mmc}(\mathrm{a}, \mathrm{b})$
(iii) $\mathrm{mmc}(\mathrm{a}, \mathrm{b}) \neq \mathrm{mmc}(\mathrm{b}, \mathrm{a})$
(iv) $\operatorname{mmc}(a, b)=\operatorname{mmc}(|a|,|b|)$

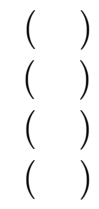

4) Foi construído com hastes de metal um losango articulado de lado igual a $6 \mathrm{~cm}$. Denominou-se de ABCD esse losango e < o ângulo BÂD.

a) Estude as variações de área desse losango em função do ângulo 〈.

b) Para que valor de < a área do losango é máxima? Justificar.

5) Uma certa substância se decompõe aproximadamente segundo a lei $Q(t)=K \cdot 2^{-0,5 t}$ em que $\mathrm{K}$ é uma constante, $\mathrm{t}$ indica o tempo em minutos e $\mathrm{Q}(\mathrm{t})$ indica a quantidade da substância, em gramas, no instante t. Considerando os dados desse processo de decomposição mostrados no gráfico a seguir, determine os valores de $\mathrm{K}$ e de $\mathrm{a}$.

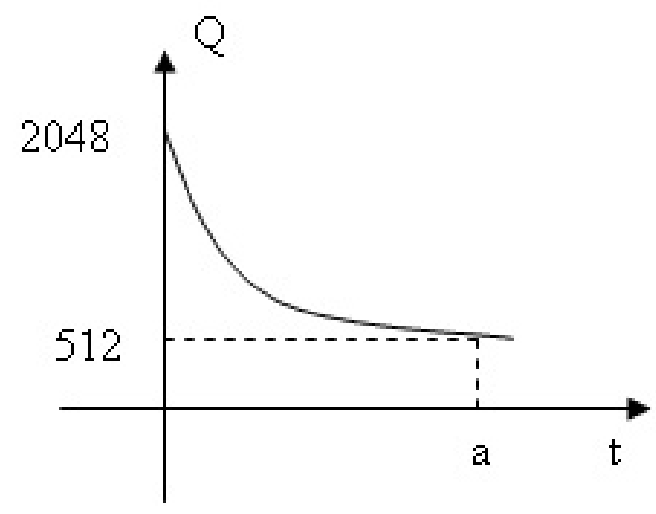


6) Esboçar, num mesmo plano cartesiano, os gráficos de $f(x)=x^{2}$ e $f^{-1}(x)$, considerando $f:[0,+\infty) \rightarrow I R$.

7) A Didática exerce importante função na sistematização e organização do ensino, no estabelecimento de elos entre as opções filosóficas e político-pedagógicas do professor e na aproximação entre teoria e prática na formação docente. Nos currículos dos cursos de formação de professores, a Didática tem a função primordial de:

a) contribuir para a fundamentação de uma prática reflexiva e crítica, garantindo a unidade entre teoria e prática.

b) assumir um caráter prescritivo da prática docente e indicar técnicas apropriadas ao fazer pedagógico.

c) contribuir com uma prática normativa, fundamentando-se em modelos já existentes e de comprovada eficiência.

d) contribuir para a formação técnica da docência, acentuando os aspectos da prática, sobretudo os de caráter normativos.

8) Avaliação da aprendizagem pode desempenhar várias funções nos processos de ensino e aprendizagem. Quando articuladas em uma prática pedagógica dinâmica, propicia o desenvolvimento do aluno, uma vez que potencializam a apropriação de conteúdos significativos, contribuindo para a construção do conhecimento e para o desenvolvimento de habilidades e de convicções. Para que a avaliação possa desempenhar suas importantes funções, o professor necessita de instrumentos para operacionalizar a sua prática. Sendo assim, é necessário:

I- respeitar os ritmos de aprendizado do aluno e considerar os instrumentos de avaliação como diagnóstico de conhecimentos e de trocas dialógicos.

II- articular os instrumentos selecionados aos conteúdos trabalhados sem exigir nos instrumentos de avaliação, uma aprendizagem que não foi solicitada no decorrer das aulas.

III- escolher os instrumentos avaliativos adequados às exigências dos conteúdos, sem precisar compatibilizá-los ao grau de dificuldade do aluno.

IV-construir instrumentos avaliativos usando uma linguagem compreensível que indique claramente os objetivos a serem atingidos pelo aluno, enfocando parte significativa dos conteúdos trabalhados em sala de aula.

Assinale a opção em que todas as afirmativas estão corretas.

a) I, III e IV.

b) I, II e IV.

c) I, II e III.

d) II, III e IV.

9) A aprendizagem é explicada por diferentes teorias cognitivas, tendo como referência os pressupostos da Psicologia Evolutiva e da Psicologia da Aprendizagem. A partir desse referencial, relacione cada abordagem teórica apresentada na primeira coluna ao seu respectivo processo de desenvolvimento da aprendizagem humana explicitado na segunda coluna. 


\begin{tabular}{|l|l|}
\hline 1. Behaviorismo & $\begin{array}{l}\text { a ( ) o desenvolvimento cognitivo é possibilitado pela interação } \\
\text { do sujeito com o outro e com o grupo social, tendo como fator } \\
\text { principal a linguagem, num processo de amadurecimento das } \\
\text { funções mentais superiores. }\end{array}$ \\
\hline 2. Sócio-histórica & $\begin{array}{l}\text { b ( ) o processo de aprendizagem humana ocorre por meio do } \\
\text { desenvolvimento de estruturas cognitivas, que se modificam por } \\
\text { meio da adaptação, envolvendo a assimilação e a acomodação, } \\
\text { mediada pela equilibração dos esquemas cognitivos. }\end{array}$ \\
\hline 3. Inteligências múltiplas & $\begin{array}{l}\text { c ( ) a aprendizagem acontece pelo condicionamento do compor- } \\
\text { tamento, por meio do processo de estímulo-resposta, dependen- } \\
\text { do das variáveis e se originam no ambiente. }\end{array}$ \\
\hline 4. Epistemologia genética & $\begin{array}{l}\text { d ( ) para que ocorra o desenvolvimento da aprendizagem hu- } \\
\text { mana, é preciso identificar as capacidades cognitivas mais eviden- } \\
\text { tes do indivíduo com o objetivo de explorá-las e desenvolvê-las. }\end{array}$ \\
\hline
\end{tabular}

Assinale a alternativa cuja relação da primeira coluna com a segunda está correta.

a) $1 \mathrm{a} ; 2 \mathrm{~b} ; 3 \mathrm{c} ; 4 \mathrm{~d}$.
b) $1 \mathrm{c} ; 2 \mathrm{a} ; 3 \mathrm{~d} ; 4 \mathrm{~b}$.
c) $1 \mathrm{~b} ; 2 \mathrm{c} ; 3 \mathrm{a} ; 4 \mathrm{~d}$.
d) $1 \mathrm{~d} ; 2 \mathrm{~b} ; 3 \mathrm{c} ; 4 \mathrm{a}$.

10) Para realizar uma prática integradora e desvencilhada tanto da divisão e da fragmentação do trabalho quanto do controle hierárquico, a instituição escolar necessita criar condições geradoras de uma outra forma de organização do trabalho pedagógico capaz de romper com práticas educativas fragmentadas.

Nessa perspectiva, analise criticamente a organização pedagógica do currículo escolar, que favoreça a ruptura de práticas educativas segmentadas, antidemocráticas e discriminatórias.

Nota: As referidas questões foram pinçadas de obras indicadas no Projeto Político Pedagógico do curso de Licenciatura em Matemática, bem como de questões disponíveis na internet. Portanto, não foi objetivo da pesquisa elaborar questões, mas tão somente reunir problemas que fizessem referência ao ENFGE. 